\title{
INTERVIEW
}

For reprint orders, please contact: reprints@futuremedicine.com

\section{Biogen's portfolio and research efforts in multiple sclerosis: an interview with Dr Ralph Kern}

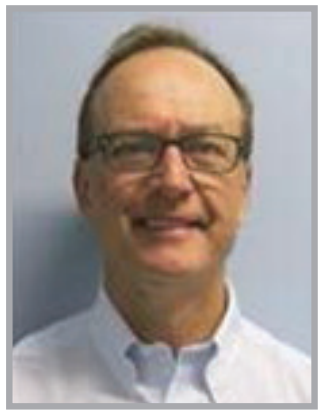

Dr Ralph Kern* speaks to speaks to Laura Dormer, Commissioning Editor: Dr Ralph Kern is Senior Vice President and Head of Worldwide Medical at Biogen in Cambridge, MA, USA. In this role, he oversees Biogen's global therapeutic, regional and country medical teams, global medical operations, as well as medical research and scientific communications functions. Prior to joining Biogen, he was head of the Neuroscience Medical Unit at Novartis Pharmaceuticals Corporation and held various medical and commercial leadership roles at Genzyme Corporation. Prior to joining industry, he was a consultant neurologist at Mount Sinai Hospital and the University Health Network in Toronto, Ontario and was head of the neurology postgraduate academic program at the University of Toronto. Ralph completed neurology postgraduate training at McGill University and completed a masters of health administration from the Institute for Health Policy, Management and Evaluation at the University of Toronto. He is a member of the College of Physicians and Surgeons of Ontario and the Royal College of Physicians and Surgeons of Canada.

First draft submitted: 29 September 2016; Accepted for publication: 25 November 2016; Published online: 10 January 2017

Q Can you introduce yourself \& give us an overview of Biogen's multiple sclerosis research?

I am Senior Vice President and Head of Worldwide Medical at Biogen. Biogen has been a pioneer in multiple sclerosis (MS) research for 25 years, developing the most therapies in this area. Our goal has been to create new solutions and therapies for patients and improve MS care overall for patients and their families, and we believe that the best way to achieve this is to continually innovate. At the European Committee for Treatment and Research in MS (ECTRIMS) 2016 Congress, we are delighted at the diversity of the data being presented, of which there are two main parts.

First, there is data around the Biogen portfolio. Biogen produces the most widely adopted oral therapy for MS
- TECFIDERA ${ }^{\circledR}$ (dimethyl fumarate). We have also introduced the new therapy ZINBRYTA $^{\circledR}$ (daclizumab), which has just been launched. We will be presenting realworld data on TECFIDERA, and also aim to ensure clinicians have an appreciation of the unmet needs that can be addressed with ZINBRYTA.

Second, is the clear focus we have on improving patient care. At ECTRIMS we are presenting on a very large European study, obtaining information from 16,000 patients across 16 countries via our partnership with the MS Burden of Illness study group, which gives us a real foundation to having those discussions. [1].

Q Can you tell us more about

TECFIDERA \& ZINBRYTA \& the data being presented at ECTRIMS?

Historically, Biogen developed injectable

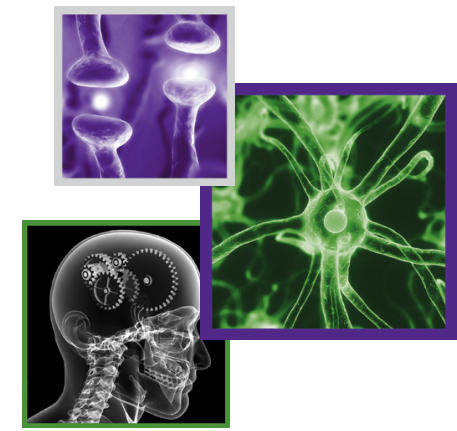

\section{KEYWORDS}

- ECTRIMS • multiple sclerosis

- therapeutics 
therapies, primarily interferons, which at that time were considered the platform therapies for the broadest use across MS patients. However, these did not fully address the needs of patients with very high disease activity or more aggressive disease. TYSABRI ${ }^{\circledR}$ (natalizumab) was therefore brought into the MS treatment arena, which is an injectable therapy that prevents immune cells from accessing the immune system. TYSABRI has been in use for 10 years now, and we are continually learning about this drug. Data are being presented at ECTRIMS that show that outcomes with TYSABRI are still strong after 10 years, and also that results are robust in different patient subgroups [2]. For example, patients with different levels of disability at the start of therapy have an equal opportunity to respond to TYSABRI, and the 10-year data indicate that treatment is sustained over that time period.

TECFIDERA was then introduced, which was a wonderful addition for MS patients because it is a high-efficacy therapy that is available in a twicedaily oral form. It, therefore, removed the need for frequent injections and hospital care/administration. Importantly, experience with TECFIDERA has now expanded beyond the clinical trials, and real-world comparative effectiveness and safety data are being presented at ECTRIMS. This extends the observations made in the smaller clinical trial population to a broader real-world population. To accomplish this, Biogen has formed a partnership with the MS patient registry, MSBase [3,4]. MSBase really crosses boundaries, showing experience of a really broad range of MS patients across different countries. It also allows us to make comparisons between therapies. In the MSBase analysis it was observed that TECFIDERA demonstrated better outcomes than the platform therapies (the original instalment of MS therapy injectables), including teriflunomide (another oral therapy), and outcomes were equal to those with fingolimod (also an oral therapy). This is an important observation, as it shows that early, convenient treatment with a very effective oral therapy can be introduced at an early disease stage. We now know that early intervention with an effective and appropriate treatment can really make a difference in preventing and delaying long-term disability, so this creates a huge opportunity for patients.

Following TECFIDERA, ZINBRYTA was introduced. The data being present at ECTRIMS expands the data that were the basis for ZINBRYTA's approval (the DECIDE and
SELECT studies) [5,6]. The expanded data are important in demonstrating that the treatment effect of ZINBRYTA is sustained and durable over time. ZINBRYTA has a new mechanism of action, and is also a convenient, monthly subcutaneous injection that patients can administer themselves. Importantly, ZINBRYTA does not deplete the immune system, which most other MS therapies do, and which also raise questions around reversibility. ZINBRYTA is very quickly reversible, and therefore may address an unmet need as patients' transition between therapies.

The data being presented at ECTRIMS on ZINBRYTA are twofold. First, there is the long-term extension data demonstrating that the Phase III data can be sustained over time. Second, the data look at the 'no evidence of disease activity' (NEDA) measure of MS outcome. NEDA is interesting because it is a composite measure of clinical activity plus traditional MRI activity and also brain volume changes. It is probably the best measure to indicate a lack of disease activity. The NEDA data for ZINBRYTA show that it performed better than the traditional platform interferon therapy AVONEX ${ }^{\circledR}$ (IFN- $\beta$-1a). This shows that ZINBRYTA has a unique set of attributes that may address patient needs.

\section{Q Alongside partnering with MSBase, in} what other ways is Biogen engaging with the patient community to better understand the burden of illness?

Biogen engages with the patient community in several ways. First, we listen. From patient summits it is clear that data related to patient needs and burden of disease are key to patients, and it is very important that they have a voice with payers, political organizations and MS societies to articulate their needs. We are moving into a world of increasingly complex therapies, and the default position is to not fully address patient needs. Obtaining information about patient unmet need from 16,000 patients across 16 countries is a real foundation to having those discussions.

Second, Biogen listens carefully to patients and patient organizations around the world, in terms of understanding patient treatment preferences. This allows us to determine the need for different formulations and determine the best delivery device for our therapies. For example, one of our therapies is delivered via monthly subcutaneous injection, such as ZINBRYTA.

Biogen also supports patient organizations in advocacy efforts via education. We want 
to make sure these organizations have all the information they need, so that when they have conversations regarding their advocacy efforts, both externally and with their members, they are fully informed.

\section{Q Looking forward, can you elaborate on Biogen's main areas of research focus?}

There are two areas of focus at present. One is how to optimize the use of existing therapies. The Multiple Sclerosis Partners Advancing Technology and Health Solutions (MSPATHS) program is something we are currently working on, and is a way of organizing MS care using very standardized outcome measures. This allows us to quantify the improvements and the needs that patients have throughout their journey and help set up learning health care systems.

A second area of focus relates to the fact that we are going into a new phase of MS care where managing inflammation in the brain can be optimized to a certain point. This is important because if we can optimize the treatment of inflammation, brain lesions could be prevented from forming and causing new damage. But the reality is that at the time of diagnosis and entering the treatment journey, patients already have disease. So there is a need to repair the nervous system, even in the event that we have the best possible treatment to control brain inflammation. Biogen is approaching this by looking at treatments that promote remyelination and repair, in which we have active research programs.

It is still early in that research journey but we are very committed to both remyelination and repair with existing opportunities and also looking at the underlying science of remyelination and repair. One of our science teams is focused entirely on this and we believe there might be new targets that emerge that may be addressable with therapy. Making that happen is the next phase in our pioneer research in MS.

\section{Disclaimer}

The opinions expressed in this interview are those of the interviewee and do not necessarily reflect the views of Future Medicine Ltd.

\section{Financial \& competing interests disclosure}

$R$ Kern is an employee of Biogen (MA, USA). R Kern has no other relevant affiliations or financial involvement with any organization or entity with a financial interest in or financial conflict with the subject matter or materials discussed in the manuscript apart from those disclosed.

No writing assistance was utilized in the production of this manuscript.

\section{References}

1 Kobelt G, Berg J, Gannedahl M, Eriksson J, Thompson A, MS BOI Study Group. Cognition, fatigue and health-related quality of life in patients with multiple sclerosis: results from a european-wide study. Presented at: 32nd Congress of the European Committee for Treatment and Research in Multiple Sclerosis. London, UK, 14-17 September 2016 (Poster P871).

2 Fox RJ, Chan A, Gold R et al. Absolute lymphocyte count and lymphocyte subset profiles during long-term treatment with delayed-release dimethyl fumarate in patients with relapsing-remitting multiple sclerosis. Presented at: 32nd Congress of the European Committee for Treatment and Research in Multiple Sclerosis. London, UK, 14-17 September 2016 (Poster P716).

3 MSBase - Multiple Sclerosis Database. www.msbase.org

4 Butzkueven H, Chapman J, Cristiano E et al. MSBase: an international, online registry and platform for collaborative outcomes research in multiple sclerosis. Mult. Scler. 12(6), 769-774 (2006).
5 Kappos L, Wiendl H, Selmaj K et al. Daclizumab HYP versus interferon beta-1a in relapsing multiple sclerosis. N. Engl. J. Med. 373(15), 1418-1428 (2015).

6 Phillips G, Guo S, Bender R, Havrdová E, Proskorovsky I, Vollmer T. Assessing the impact of multiple sclerosis disease activity and daclizumab HYP treatment on patient-reported outcomes: results from the SELECT trial. Mult. Scler. Relat. Disord. 6, 66-72 (2016). 